\title{
EXPLORING SELF-MENTION IN THE YEMENI EFL ARGUMENTATIVE PARAGRAPHS ACROSS THREE PROFICIENCY LEVELS
}

\author{
Ali ALWARD \\ University of Science and Technology, Yemen \\ a.alward@ust.edu
}

Manuscript received 6 July 2019

Manuscript accepted 25 Nov 2019

*Corresponding author

10.33736/ils.1693.2019

\begin{abstract}
Self-mention used by university-level Yemeni writers is regarded as a challenging task. The overuse use of this feature is often considered as less formal and objective in academic writing. Despite the significance of this feature in academic writing, previous studies were mostly conducted in the Western cultural context. Research on self-mention produced by EFL learners of Arabic cultural background seems to be overlooked. Therefore, this study aimed to explore and compare the use of the firstperson pronouns across three proficiency levels in an argumentative paragraph written by 80 third-year undergraduate students. Data were collected, assessed by ELT specialists, and then quantitatively analyzed. The results revealed that Yemeni EFL learners make extensive use of the first-person pronouns in their argumentative paragraphs. Differences were found in the occurrences of the first-person pronouns across three proficiency levels. The results also indicated that learners with a high proficiency level tend to use the first-person pronouns less than learners at low and intermediate proficiency levels. Since low-proficient learners rely more on the use of the first-person pronouns than those at higher levels, learners need to be exposed to a variety of strategies of how they can project their voice appropriately in their written texts.
\end{abstract}

Keywords: Self-mention, first-person pronouns, argumentative Paragraph, EFL proficiency level

\section{Introduction}

The concept of self-mention is described by Hyland (2005) as the use of the firstperson pronouns and possessive adjectives to provide interpersonal information. The rules governing the personal pronouns are easy to learn, but the rules that

Exploring Self-Mention in The Yemeni EFL Argumentative Paragraphs Across Three Proficiency Levels 
regulate their use appear to be challenging for non-native speakers of English (Natsukari, 2012). Exploring self-mention in relation to the proficiency levels has received little attention (Choung \& Oh, 2017; Lee \& Oh, 2018; McCrostie, 2008; Oh \& Kang, 2013). This issue has been reported by several scholars that written texts by non-native speakers have been characterized by having greater subjectivity (Gilquin \& Paquot, 2008; Herriman \& Aronsson, 2009; Hinkel, 1999; Ishikawa, 2008; Luzon, 2009; Natsukari, 2012; Petch-Tyson, 1998). The use of the first-personal pronouns makes academic writing less formal, and objective (Biber, Johansson, Leech, Conrad \& Finnegan, 1999; Chafe, 1982; Fowler \& Aaron, 2010; Korhonen \& Kusch, 1989; Kuo, 1999; Smith, 1986). As Milton (1999) states, personal pronouns used by nonnative English speakers are associated with conversation. While there has been research into the use of the first-person pronouns in academic writing, few studies have been reported in L2 writing, particularly the essays produced by learners with lower proficiency levels (Chang, 2015; McCrostie, 2008). Therefore, the aim of this study is to contribute to the research on the learners' use of the first-person pronouns used by Yemeni EFL learners of Arabic cultural background through comparing the occurrences and distribution of these features across three proficiency levels (i.e. low, intermediate, advanced). This comparison attempts to provide an insight into how Yemeni EFL learners of English project their voice in their argumentative writing.

\section{Review of Literature}

\section{Self-Mention and Proficiency Level}

The concept of 'self-mention' is defined as those features which refer to the use of first-person pronouns and possessive adjectives by speakers/writers (Hyland, 2001). These features can play an important role in the text as writers decide to project their voice to portray themselves as reliable members in community. It was believed that self-mention is contrary to the requirements of objectivity and formality in academic writing (Maclntyre, 2017). Yet, through appropriate use of self-mention, writers can establish a positive self-representation and shape strong writer-reader relationship (Mur Duenas, 2007) and attain their credibility (Hyland, 2001). It has been observed that the use of self-mention can be a challenging task for native speakers and much more so for non-native speakers (Atkinson, 2004). In regard to the proficiency level, previous results revealed that low achieved learners tend to use more self-mentions than their counterparts at higher levels (Choung \& Oh, 2017; McCrostie, 2008; Neff et al., 2004).

\section{Argumentative Writing}

The genre of argumentative writing is defined as a kind of writing which attempts to persuade someone of something (Intraprawat, 2000). Research into the genre of argumentative essay reports that students experience difficulty in assembling written arguments in their college years (Overbay 2003). According to Tanko and Tamasi (2008), research on argumentative texts of university students has become a

Exploring Self-Mention in The Yemeni EFL Argumentative Paragraphs Across Three Proficiency Levels 
major concern for people in tertiary educational institutions. Along the same line, Henry and Roseberry (1997) emphasized that the most common place for the genre of argumentative writing is in the higher educational setting. However, due to its nature, it was considered as the most difficult type of writing (McCann, 1989). The present study focused on argumentation because this genre has been identified in several studies as a central component of university writing (Reid, 2001).

\section{Related Studies}

In the last two decades, self-mention in English as a second and foreign language has been investigated (e.g. Chávez Muñoz, 2013; Fortanet, 2004; Hyland, 2002; Kim, 2009; Luzón, 2009; MacIntyre, 2017; Matsuda, 2001; Martínez, 2005; Mur Dueñas, 2007; Natsukari, 2012; Tang \& John, 1999). However, investigation into the actual use of self-mention has been almost on Western context (e.g. Chávez Muñoz, 2013; Luzon, 2009; MacIntyre, 2017). As Hyland and Jiang (2017) confirm, research into self-mention used by non-native speakers of English seems to be overlooked and incomplete. In the following section, more recent studies on self-mention are discussed.

While several studies have investigated self-mention on research articles of different disciplines, few studies have focused on second language writing (Chang, 2015; Hyland \& Jiang, 2017). For instance, Riyanti (2015) explored the voice and how it was established in second language writing. The findings of the study revealed that the concept of voice can broadly refer to many things which can be confusing to second language writers who are trying to position themselves to the expectations of the audience. Furthermore, the second language writers struggle to make their voice strong which are triggered by many factors.

Some other studies have focused on examining the use of first-person pronouns in the argumentative genre. For example, Chang (2015) analyzed and compared the use first singular pronoun 'I' between native speaker of English and Korean writers using argumentative writing. The findings revealed that the frequent use of the pronoun was relatively higher in the Korean learners' corpus than that in the native speakers' corpus. In the same line with Chang (2015), Lee and Deakin (2016) investigated the use of the first-person singular pronoun in argumentative writing. The use of I was compared within different proficiency levels in personal writing. The results revealed that learners used less pronouns of personal nature in their argumentative essays which is used mostly to convey opinions in formulaic expressions.

Apart from the second language writing, recently a significant number of studies have investigated self-mention through the use of the first-person pronouns in research papers. For example, Abdi (2015) attempted to compare the use of selfmention features within interdisciplinary research between L1 and L2 of Applied linguistics, Mechanic and Engineering, and Medicine. The purpose of his study was to highlight both interdisciplinary and intercultural differences. The findings of his study indicated that the use of first-person pronouns appears to be more in Applied Linguistics than the other two disciplines. Additionally, the findings revealed that $L 2$

Exploring Self-Mention in The Yemeni EFL Argumentative Paragraphs Across Three Proficiency Levels 
writers tend to underuse the first-person pronouns in Applied linguistics and overuse a higher level of authorial identity than L1 writers in the other disciplines.

In the same line of investigation, Shelton (2015) compared the use of firstperson pronouns in three major categories i.e. social sciences, arts, and humanities. The findings revealed that writing in the first-person pronouns with active voice in more direct and understandable text is preferred.

Similarly, Leadham (2016) compared the use of self-mention features in three corpora: biology, Economics, and Engineering written by English native speakers and Chinese students. The findings displayed that Chinese writers tend to overuse firstperson plural pronouns 'we' while native speakers tend to use first singular pronoun 'I'.

In their corpus-based study, Dobakhti and Hassen (2017) examined the degree of authorial presence through the use of first-person pronouns in 150 research articles of Applied Linguistics. The findings revealed that a greater use of selfmention by qualitative research writers compared with their quantitative counterparts. These findings suggest that the degree of personal involvement is determined by the research design.

In a more recent study, Lau (2018) conducted study on how professional writers in the contrasting discipline of literature, a field which is interpretive, and computer science, an empirical field, use first-person pronouns. The findings of the study suggest that the dichotomy between hard and soft sciences may not apply in all cases. The pronoun 'we' was most frequent in both sub-corpora.

Isler (2018) compared the use of first-person pronouns and their underlying functions in 20 master's theses written in English by Turkish authors and 20 research articles written in English by non-native Turkish authors. Results revealed a remarkable difference in the use of the first-person pronouns and the functions they have. Unlike non-Turkish writers who use these pronouns more frequently, Turkish writers tend to use these pronouns rarely.

In a more recently published study, Ismail (2019) analyzed the Malaysian Muslim tertiary level students' written English in expressing Islamic related matters. The analysis focused on the use of personal pronouns in communicating their religious teachings. The findings revealed that the plural first-person 'we' and 'us' were most used in writing to strengthen their Islamic relationship and views within Muslim community.

From the review of the previous studies, it is clear that existing studies on selfmention have largely been on comparison of the use of self-mention between native and non-native speaking writers of research articles of different disciplines while these features appear to be overlooked in second language writing, particularly by learners of Arabic cultural background. Research into self-mention received quite little attention in L2 writing and learner corpus research (Chang, 2015; Hyland \& Jiang, 2017). Therefore, this study aims to explore and compare how self-mention was manifested in English as a second and foreign language across three proficiency levels. 


\section{Methodology}

The study invovled 80 undergraduate third-level university students enrolled in the English program, Faculty of Languages, Sana'a University. All participants were nonnative speakers of English and their ages range between 20 and 23. All the participants were informed of the general purpose of the study and they willingly agreed to take part in this study. In the process of data collection, the participants were informed of the procedures that would be used to collect the data, and assured that there were no potential costs or risks. Participants were classified according to their proficiency levels. The participants with a lower proficiency level were $n=36$ and the participants with an intermediate proficiency level were $n=27$ while participants with a higher proficiency level were $n=17$.

\section{Instrument}

The instrument of this study is an argumentative paragraph as an appropriate instrument to collect such type of data (Hyland \& Milton, 1997; Oller, 1983; Plakans, 2008). The students were asked to write an argumentative paragraph of not more than 250 words during the lecture of their writing class. The writing task reads: "Write an argumentative paragraph in less than 250 words in which you support your view that Internet has more advantages than disadvantages. You should organize, demonstrate, and express your ideas in a persuasive manner that others will agree with you".

\section{Data Collection and Analysis}

The data was collected from 80 scripts written by third-year undergraduate students. The scripts were then marked by two raters using EFL composition profile Jacobs, Zinkgraf, Wormuth, Hartfiel and Hughey (1981). Then, each subject's score was averaged to create a single score. The group scored between 65 and 79 is the low-level group and the group scored between 80 and 89 is the intermediate level group while the group scored between $90-100$ is the high-level group (See Table 1). Having three proficiency levels were established, three rounds of reading were made: device identification, frequency computation, and comparative demonstration. In the first round, the researcher carefully read the text word by word highlighting the features related to self-mention in the text through using green color. The second round was to establish the frequency computation. In the third round, Post-hoc of One-way ANOVA was used to show where the differences among the three proficiency levels occur. 
Table 1

Test scores across three proficiency levels

\begin{tabular}{ccc}
\hline Proficiency Level & Number of Participants & Score \\
\hline Low & 36 & $65-79$ \\
Intermediate & 27 & $80-89$ \\
Advanced & 17 & $90-100$ \\
\hline
\end{tabular}

\section{Results and Discussion}

The results of the statistical analysis of the first-person pronouns were provided in Table 2 and Figure 1 below using the Post hoc of One-way ANOVA. The results are shown in three columns which indicate that there are significant differences between the three levels. As Table 2 indicates, the overall frequency of the firstperson pronouns used by the low proficient learners is higher than those at intermediate and advanced level $(39,25,17)$ respectively.

Table 2

Distribution of occurrences of first-person pronouns across three proficiency levels

\begin{tabular}{c|c|c|c|c}
\hline \multirow{2}{*}{ Level } & \multirow{2}{*}{$\mathrm{N}$} & \multicolumn{3}{|c}{ Subset for alpha=.05 } \\
\cline { 3 - 5 } & & 1 & 2 & 3 \\
\hline Low & 36 & & & $\mathbf{3 9}$ \\
\hline Int. & 27 & & $\mathbf{2 5}$ & \\
\hline Adv. & 17 & $\mathbf{1 7}$ & & \\
\hline Sig. & & 1.000 & 1.000 & 1.000 \\
\hline
\end{tabular}

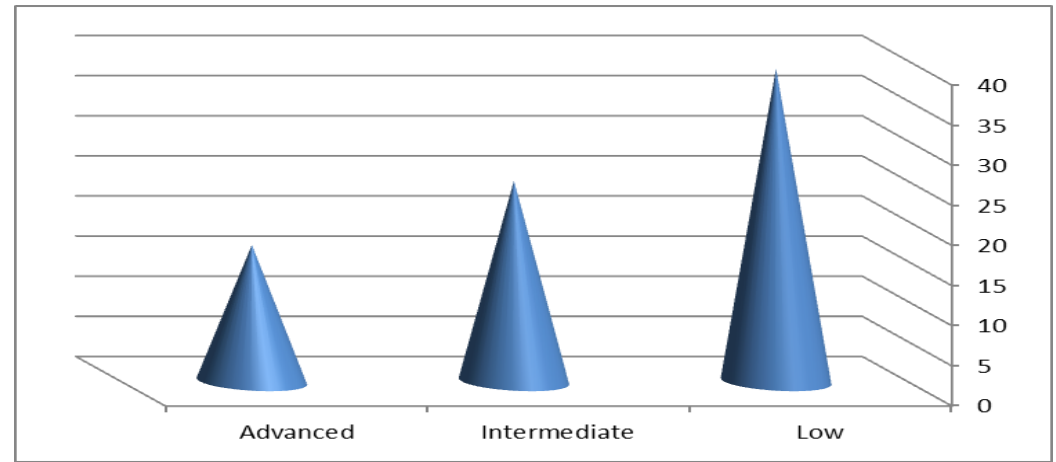

Figure 1. Frequency of the First-person Pronouns across three Proficiency Levels

The findings indicate that students of high proficiency level tend to use the first-person pronouns less frequently than students at intermediate and low proficiency levels. The frequency of the first-person pronouns drops as the

Exploring Self-Mention in The Yemeni EFL Argumentative Paragraphs Across Three Proficiency Levels 
proficiency level increases. In other words, the higher the proficiency the students have the fewer number of the first-person pronouns are used. These findings are similar to earlier studies in relation to the quantity of the first-person pronouns used by learners at different proficiency levels of EFL learners (e.g. Lee \& Deakin, 2016; Oh, 2007; Storch, 2009). The extracts below demonstrate the learners' use of the first-person pronouns across three proficiency levels:

Low.

Ex1: "Internet is an important thing in our life. We can get a lot of benefits from internet. Actually, internet is a great thing if we use properly. It helps us in many

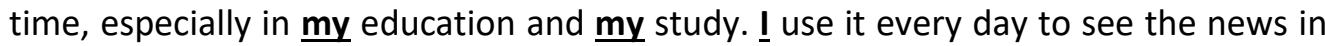
English. Internet gave us all what we have and more and more that it has made our big world as a small village. It could be dangerous if we misuse it as there are so many sexual websites."

Ex2: "Internet became important for our needs in different stages of our age. It helps us in many aspects, and also it affects us in many other aspects like our eyes, backs and waste our time. internet are very important for everyone in our world today. We need internet to do our jobs easily. I think we cannot do all work in a short time."

Ex3: "We must mention that internet will save our history in an electronic form, which will be probably very easy for us to retrieve and display. The internet gave us freedom of ideas and information. we can play games, chat and do many other aspects. Internet invention changed the face of our earth."

\section{Intermediate.}

Ex 4: "Internet is one the most important service for us. It is used in the companies, universities all over the world. It brought us together to share knowledge, love, and many other things.

Ex 5: "Internet is now a part of our regular life. It can keep people from different countries to be connected with each other. Moreover, by internet, we can easily find any kind of information that we are looking for."

Ex. 6: Internet can be used for almost everything. For example, we can find anything in the world. Also through email, we can solve many problems and provide solutions for any issue we are having."

\section{Advanced.}

Ex 7: "In our daily life, Internet is used in different fields such as chatting, shopping, medicine, and business. All companies around the world use internet to make their work done better. It can help us do many job effectively. Although Internet has 
advantages, there are some other disadvantages. For example, people who remain in front of computers for a long time will have problems with their eyes and backs."

Ex 8: "Internet can be harmful. For example, we just by one click can easily find unethical sites. So, we should be careful when they find such bad sites and find ways of getting them blocked."

Ex 9: "Internet has a wide range of uses and play an important role within our society as it can perform all kinds of work. For example, we can forecast the weather, do business reports, and carry out a scientific research."

The extracts above show that first-person pronouns appear to be more frequently used by low proficient learners than those at intermediate and advanced levels. One possible reason may be attributable to the learners' weakness in $\mathrm{L} 2$ is the learners' lack of vocabulary. As Hinkel (2005) argues, EFL writers often repeat the same idea which is probably due to the lack command of $L 2$ vocabulary.

It was noticed that a high number of occurrences of 'I' collocated with the cognitive verb 'think' was frequently used in the argumentative paragraphs This finding confirms what previous studies claim that the phrase I think is excessively used in the EFL writing essays (Ishikawa, 2008; Natsukari, 2012). Below are some extracts in which the expressions of ' $/$ think' is used.

Ex. 10: "I think that the internet is a very useful tool if it is only used well. Otherwise, mistreatment of the internet would lead to disastrous consequences."

Ex. 11: "I think that we can use it in our life to make our life easy to go like the other country. For example, we can use it for something that we need for life."

Ex. 12: "At last I think that internet is a weapon that has two edges. So we can use it in right way, and it will benefit us or use it in wrong way and it will confuse us."

Ex. 13: "To conclude, the internet has many advantages and disadvantages, but I think the advantages are more than disadvantages."

Other expressions such as 'in my opinion' and 'in my point of view' were also found to be common. These expressions indicate that the writers' claims are based on their opinions and that the readers may or may not have the same opinions with the writers (Martin-Martin, 2008; Salager-Meyer, 1994). This finding was also confirmed in previous studies that NNSs students are far more likely to rely on particular expressions when they convey their personal opinions (Petch-Tyson, 
1998; Yoon \& Polio, 2017). The extracts below demonstrate the learners' use of the expressions of personal opinions.

Ex 14:"In my opinion, I find internet is very important for wise people. It is really important if we used it properly."

Ex 15: "In my point of view, if we use internet, it can help us in many ways in our life. If we only understand the benefits of the internet, then no one will use it wrongly."

On the other hand, the use of the first-person plural pronouns (we, our, us) appear to be used more frequently than the first the singular pronouns (I, my, me). This is possibly due to the writers' unwillingness to promote for their individual identity or being involved in the personal claim (Hyland, 2002; Kuo, 1999). Another possible reason is that Yemeni Arab learners belong to a collectivistic culture (Hofstede, 1991) in which writers tend to adopt a holistic way of thinking (Hannover \& Kühnen, 2005). As Naj and Choi (2009) argue, participants who are collectivistic oriented prefer to use first-person plural possessive pronouns. The findings also support the believe that self-mention may differ according to the writers' cultural background. (Carter-Thomas \& Chambers, 2012).

\section{Conclusion}

The present study aimed to explore and compare the use of the self-mention features in the Yemeni EFL undergraduate argumentative paragraphs across three Proficiency levels. The findings revealed that low proficient writers tend to use more first-person pronouns than those at intermediate and advanced writers. One of the possible explanations for low-proficient students' overuse of the first-person pronouns may be they lack vocabulary and knowledge unlike students at higher proficiency levels who seem to have awareness of the appropriate use of the firstperson pronouns. Since the writers of the current study belong to what is called a 'collectivistic culture', they tend to adopt a holistic way of thinking by relying more on the first plural pronoun 'we' than 'I' in their paragraphs. The overuse of expressions such as 'I think' and 'in my opinion/point of view' were also common in the paragraphs as writers' arguments are based on their opinions. Regarding the findings and implications, the present study was limited to explore self-mentions only in the argumentative genre. Therefore, the findings of this study cannot be generalizable to other genres. Further research should take into account the comparison of the use of first-person pronouns in two different genres. Owing to the multiple functions of the first-person pronouns, future study should also examine the functions of the first-person pronouns from pragmatic perspective. 


\section{References}

Abdi, J., \& Farrokhi, F. (2015). Investigating the projection of authorial identity through first-person pronouns in L1 and L2 English research articles. International Journal of Language and Literature, 3(1), 156-168.

Atkinson, D. (2004). Contrasting rhetorics/contrasting cultures: Why contrastive rhetoric needs a better conceptualization of culture. Journal of English for Academic Purposes, 3(4), 277 - 289.

Biber, D., Johansson, S., Leech, G., Conrad, S., Finegan, E., \& Quirk, R. (1999). Longman grammar of spoken and written English. London: Longman.

Carter-Thomas, S., \& Chambers, A. (2012). From text to corpus A contrastive analysis of first person pronouns in economics article introductions in English and French. Corpus-informed Research and Learning in ESP: Issues and Applications, 52(1), 1-28.

Chafe, W. L. (1982). Integration and involvement in speaking, writing, and oral literature. In D. Tannen (Ed.), Spoken and written language: Exploring orality and literacy (pp. 35-53). Norwood, NJ: Ablex.

Chang, J. Y. (2015). A comparison of the first-person pronoun 'I' in NS and Korean NNS corpora of English argumentative writing. English Teaching, 70(2), 83106.

Chávez Muñoz, M. (2013). The "I" in interaction: authorial presence in academic writing. Revista de lingüística y lenguas aplicadas, 8(1), 49-58.

Choung, Y., \& Oh, S. Y. (2017). A systemic functional study of thematic organization in the English writing of Korean college students. English Teaching, 72(3), 1919-144.

Dobakhti, L., \& Hassan, N. (2017). A Corpus-based study of writer identity in qualitative and quantitative research articles. 3 L: Language, Linguistics, Literature, 23(1),1-14.

Fortanet, I. (2004). The use of 'we' in university lectures: Reference and function. English for Specific Purposes, 23(1), 45-66.

Fowler, H. R., \& Aaron, J. E. (2010). The little, brown handbook. New York: Pearson Education.

Gilquin, G., \& Paquot, M. (2008). Too chatty: Learner academic writing and register variation. English Text Construction, 1(1), 41-61.

Hannover, B., \& Kühnen, U. (2005). Culture, context, and cognition: The semantic procedural interface model of the self. European Review of Social Psychology, 15(1),297-333.

Henry, A. \& Roseberry, R. (1997). An investigation of the functions, strategies and linguistic features of the introductions and conclusions of essays. System, 25(4), 479-495.

Herriman, J., \& Aronsson, M. B. (2009). Themes in Swedish advanced learners' writing in English. In K. Aijmer (Ed.), Corpora and language teaching (pp. 101-120). Amsterdam: John Benjamins.

Hinkel, E. (1999). Objectivity and credibility in L1 and L2 academic writing. In E. Hinkel (Ed.), Culture in second language teaching and learning (pp. 90-108). Cambridge: Cambridge University Press.

Exploring Self-Mention in The Yemeni EFL Argumentative Paragraphs Across Three Proficiency Levels 
Hinkel, E. (2005). Hedging, inflating, and persuading in EFL academic writing. Applied Language Learning, 15(1 \& 2), 29-53.

Hofstede, G. (1991). Cultures and Organizations: Software of the Mind. London: McGraw-Hill.

Hyland, K. (2001). Humble servants of the discipline? Self-mention in research articles. English for specific purposes, 20(3), 207-226.

Hyland, K. \& Jiang, F. (2017). 'The fact that': Stance nouns in disciplinary writing. Discourse Studies, 17(5), 529-550.

Hyland, K. (2002). Authority and invisibility: Authorial identity in academic writing. Journal of Pragmatics, 34(8), 1091-1112.

Hyland, K. (2005). Stance and engagement: A model of interaction in academic discourse. Discourse Studies, 7(2), 173-192.

Hyland, K., \& Milton, J. (1997). Hedging in L1 and EFL student writing. Journal of Second Language Writing 6(2), 183-206.

Intraprawat, P. (2000). Writing an argumentative essay. Nakorn-radchasima: Suranaree University of Technology Press.

Ishikawa, S. (2008). Eigo corpus to gengo kyoiku English corpus and language education. Tokyo: Taishukan.

Isler, C. (2018). The use of first-person pronouns in Master's theses written in English by Turkish authors. Journal of English Language and Education, 4(1), 12-20.

Ismail, A. A. M. (2019). Epistemic stance personal pronouns in Malaysian tertiary level ESL. Islamic based written tasks. Journal of Research and Innovation, 6(1),1-14.

Jacobs, H.L., Zinkgraf, S.A., Wormuth, D.R., Hartfiel, V.F., \& Hughey, J.B. (1981). Testing ESL composition: A practical approach. Rowley, Mass.: Newbury House Publishers, Inc.

Kim, C.-K. (2009). Personal pronouns in English and Korean texts: A corpus-based study in terms of textual interaction. Journal of Pragmatics, 41(10), 20862099.

Korhonen, R., \& Kusch, M. (1989). The rhetorical function of the first-person in philosophical texts-The influence of intellectual style, paradigm and language. In M. Kusch \& H. Schröder (Eds.), Text, interpretation, argumentation (pp. 61-77). Hamburg: Helmut Buske.

Kuo, C. (1999). The use of personal pronouns: Role relationships in scientific journal articles. English for Specific Purposes, 18(2), 121-138.

Lau, L. S. W. (2018). First-person pronouns in academic writing: a comparative study of journal articles in literature and computer science. International Journal of Education and Research, 49(11),341-352.

Leedham, M. (2014). Chinese students' writing in English: implications from a corpusdriven study. Oxford University Press: Routledge.

Lee, E. K., \& Oh, S. Y. (2018). Korean EFL Learners' use of I in English argumentative writing: Focusing on genre-specific and proficiency-specific characteristics. Language Research 54(2), 357-381.

Exploring Self-Mention in The Yemeni EFL Argumentative Paragraphs Across Three Proficiency Levels 
Lee, J. J., \& Deakin, L. (2016). Interactions in L1 and L2 undergraduate student writing: Interactional metadiscourse in successful and less-successful argumentative essays. Journal of second language writing, 33(1),21-34.

Luzon, M. (2009). The use of we in a learner corpus of reports written by Engineering students. Journal of English for Academic Purposes, 8(3),192-206.

MacIntyre, R. (2017). The use of personal pronouns in the Writing of argumentative essays by EFL writers. RELC Journal, 50(1),1-14.

McCann, T. M. (1989). Student argumentative writing: Knowledge and ability at three grade levels. Research in the Teaching of English, 23(1), 62-75.

McCrostie, J. (2008). Writer visibility in EFL learner academic writing: A corpus-based study. ICAME Journal, 32(1), 97-114.

Martin-Martin, P. (2008). The mitigation of scientific claims in research papers: A comparative study. IJES, 8(2), 133-152.

Matsuda, P.K. (2001). Voice in Japanese written discourse. Implications for second language writing. Journal of Second Language Writing, 10(1-2), 35-53.

Milton, J (1999). Lexical thickets and electronic gateways: Making text accessible by novice writers. In C. Candlin and K. Hyland (eds.). Writing: Texts, processes and practices, 221-243. London and New York: Longman.

Mur Duenas, P. (2007). 'I/we focus on...': A cross-cultural analysis of self-mentions in business management research articles. Journal of English for Academic Purposes, 6(2), 143-162.

Na, J., \& Choi, I. (2009). Culture and first-person pronouns. Personality and Social Psychology Bulletin, 35(11), 1492-1499.

Natsukari, Sayo. (2012). Use of I in essays by Japanese EFL learners. JALT Journal, 34(1), 61-78.

Neff, J., Ballesteros, F., Dafouz, E., Martínez, F., Rica, J. P., Díez, M., \& Prieto, R. (2004). Formulating writer stance: A contrastive study of EFL learner corpora. In Applied Corpus Linguistics (pp. 73-89). Brill Rodopi.

Oh, S. Y., \& Kang, S. J. (2013). The effect of English proficiency on Korean undergraduates' expression of epistemic modality in English argumentative writing. The Journal of AsiaTEFL, 10(4), 97-132.

Oh, S.-Y. (2007). A corpus-based study of epistemic modality in Korean college students' writings in English. English Teaching, 62(2), 147-175.

Oller, J. W., Jr. (Ed.). (1983). Issues in Language testing Research. Rowley, Mass: Newbury House.

Overbay, A. S. (2003). Persuasive Developments: Reflective Judgment and College Students' Written Argumentation. (Doctoral dissertation). Retrieved from ProQuest Dissertations and Theses.

Petch-Tyson, S. (1998). Writer/reader visibility in EFL written discourse. In S. Granger (Ed.), Learner English on computer (pp. 107-118). London: Addison-Wesley, Longman.

Plakans, L. (2008). Comparing composing processes in writing-only and reading-towrite test tasks. Assessing Writing, 13(2), 111-129.

Reid, J. (2001). Advanced EAP writing and curriculum design: What do we need to know? In T. Silva \& P. K. Matsuda (Eds.), On second language writing (pp. 143-160). Mahwah, NJ: Lawrence Erlbaum.

Exploring Self-Mention in The Yemeni EFL Argumentative Paragraphs Across Three Proficiency Levels 
Riyanti, D. (2015). An exploration of voice in second language writing. The Nebraska Educator: A Student-Led Journal, 2(1), 28-48.

Salager-Meyer F. (1994). Hedges and textual communication function in medical English written discourse. English for Specific Purposes 13(2), 149-170.

Shelton, D. C. (2015). Writing in the first-person for academic and research publication. In Proceedings of the EDSIG Conference (p. n3487).

Smith, Jr., E. L. (1986). Achieving impact through the interpersonal component. In B. Couture (Ed.), Functional approaches to writing: Research perspectives (pp. 108-119). London: F. Pinter.

Storch, N. (2009). The impact of studying in a second language (L2) medium university on the development of L2 writing. Journal of Second Language Writing, 18(2), 103-118.

Tang, R., \& John, S. (1999). The "l" in identity: Exploring writer identity in student academic writing through the first-person pronoun. English for Specific Purposes, 18(S),23-S39.

Tanko, G. \& Tamasi, G. (2008). A comprehensive taxonomy of argumentative thesis statements: a preliminary pilot study. Working Papers in Language Pedagogy, 2(1),1-17.

Yoon, H. J., \& Polio, C. (2017). The linguistic development of students of English as a second language in two written genres. TESOL Quarterly, 51(2), 275-301. 